\title{
Microstructure and Mechanical Properties of Lead-Free Solder Joints
}

\author{
P. HARCUBA ${ }^{a, *}$ AND L. TRŠKO ${ }^{b}$ \\ ${ }^{a}$ Charles University in Prague, Department of Physics of Materials, Prague, Czech Republic \\ ${ }^{b}$ Research Center of the University of Žilina, Žilina, Slovak Republic
}

\begin{abstract}
In this study we investigated the morphology and growth kinetics of the interfacial intermetallic compound layers formed between a $\mathrm{Cu}$ substrate and $\mathrm{Sn}-\mathrm{Cu}$ based solders. We simulated the wave soldering process and subsequent ageing both at different temperatures and reaction times. The near eutectic $\mathrm{Sn}-0.7 \mathrm{Cu}$ alloy and $\mathrm{Ni}$ enriched $\mathrm{Sn}-0.7 \mathrm{Cu}-0.05 \mathrm{Ni}$ alloy were studied. Moreover, we measured the tensile strength of the simulated solder joints and analyzed fracture surfaces.
\end{abstract}

DOI: $10.12693 /$ APhysPolA.128.750

PACS: 06.60.Vz, 67.80.bf, 71.20.Lp

\section{Introduction}

Solders belong to the most important materials used for joining in electronic assembly. This class of alloys with low melting point must provide both reliable electrical and mechanical connection of joints and ensure a costeffective production. Traditionally, near-eutectic $\mathrm{SnPb}$ alloys (such as $60 \mathrm{Sn} 40 \mathrm{~Pb}, 63 \mathrm{Sn} 37 \mathrm{~Pb}$ or alloys modified with small $\mathrm{Ag}$ or $\mathrm{Cu}$ addition) have been used worldwide in electronics industry.

However, the replacement of $\mathrm{Pb}$-bearing alloys is inevitable because the toxicity of $\mathrm{Pb}$. European Union directives on waste electrical and electronic equipment (WEEE) and restriction of the use of certain hazardous substances (RoHS) stipulate that electronic products sold in EU must be Pb-free. Several candidate solder systems have been developed as replacements for $\mathrm{SnPb}$ alloys. $\mathrm{Sn}-\mathrm{Ag}-\mathrm{Cu}$ based alloys with promising soldering properties belong to the group of most commonly investigated materials [1-4]. In contrast, relatively little effort has been given to the development of much cheaper Sn$\mathrm{Cu}$ alloys. It is known that the properties of these alloys can be improved by minor additions of other elements. For example, it has been shown that the addition of $\mathrm{Ni}$ could improve the soldering properties of $\mathrm{Sn}-\mathrm{Cu}$ alloys by reducing the tendency for bridging and improving the surface finish of joints [5-7].

During the soldering process, and nearly immediately upon contact between the molten solder and the solid substrate, intermetallic compounds (IMC) begin to form at the interface. The formation of an interfacial intermetallic layer is desirable to attain good bonding between the substrate and the solder. However, because of the brittleness of the intermetallics, an excessively thick layer may deteriorate the mechanical and electrical properties of the joint. Thermomechanical fatigue may cause additional growth of the IMC layer, induce internal stresses,

\footnotetext{
* corresponding author; e-mail: harcuba.p@gmail.com
}

and result in degradation of the joint. Therefore, it is extremely important to control the growth of the IMC layer.

Two IMC layers can be formed at the interface as a result of the reaction of Sn-based solder with the $\mathrm{Cu}$ substrate. A layer with a typical scallop morphology of $\mathrm{Cu}_{6} \mathrm{Sn}_{5}$ ( $\eta$-phase) is usually formed $[1,4]$. However, extensive soldering time and the high temperature of the molten solder may result in the formation of an additional thin layer of $\mathrm{Cu}_{3} \mathrm{Sn}$ ( $\varepsilon$-phase) at the $\mathrm{Cu} / \mathrm{Cu}_{6} \mathrm{Sn}_{5}$ interface.

In this work, we present the results of a study focused on assessing the effect of $\mathrm{Cu}$ content in $\mathrm{Sn}-\mathrm{Cu}$ solder and the effect of $\mathrm{Ni}$ additions on the growth kinetics of the IMC layer formed during the liquid solder/solid $\mathrm{Cu}$ substrate reaction and subsequent ageing. We also investigate the effect of $\mathrm{Cu}$ and $\mathrm{Ni}$ on the mechanical properties of simulated solder joints.

\section{Experimental}

The near eutectic $\mathrm{Sn}-0.7 \mathrm{Cu}$ (SC), and Ni enriched Sn$0.7 \mathrm{Cu}-0.05 \mathrm{Ni}(\mathrm{SCN})$ lead-free alloys were used in this investigation. Rectangular thin plates were cut from oxygen-free, high conductivity copper and used as substrates for soldering. The specimens were chemically polished in 40 vol.\% $\mathrm{HNO}_{3}$ solution in distilled water to remove the oxide film. Then the samples were cleaned with ethanol and dried with a hot-air blower. Next, a mildly activated flux was applied to the polished surface. The specimens with flux were preheated on a hot plate and dipped into the soldering bath containing about $500 \mathrm{~g}$ of molten solder. The soldering bath composition was kept constant by the continuous addition of pure tin. The composition was controlled using atomic absorption spectroscopy. By this procedure, the commonly used wave-soldering process was simulated.

A set of samples differing in bath temperature $\left(240{ }^{\circ} \mathrm{C}\right.$ to $285^{\circ} \mathrm{C}$ ) and dipping time ( $5 \mathrm{~s}$ to $6000 \mathrm{~s}$ ) was prepared from both alloys. Samples for ageing studies were dipped into the soldering bath at the temperature of 
$255^{\circ} \mathrm{C}$ for $40 \mathrm{~s}$ and subsequently aged in a furnace at temperatures of $120^{\circ} \mathrm{C}$ and $150^{\circ} \mathrm{C}$ up to 24 days.

The morphology of the interfaces was observed by light microscopy (LM). The composition of the IMC layers was determined by scanning electron microscopy (SEM) using an FEI QUANTA 200 FEG operating at $20 \mathrm{keV}$ and equipped with backscattered electron and secondary electron detectors, and an energy-dispersive X-ray spectrometer (EDX).

Samples used for measuring the mechanical properties were prepared by two methods. For studying the dependence of tensile strength of solder joints on the conditions of soldering, two pieces of copper plates with dimensions of $25 \mathrm{~mm} \times 8 \mathrm{~mm} \times 2 \mathrm{~mm}$ were fixed in a special holder so that $0.2 \mathrm{~mm}$ space was left between them. The samples with the holder were then preheated and dipped into the soldering bath. The solder filled the space between the two $\mathrm{Cu}$ parts and after cooling, a simulated solder joint was obtained. However, due to an insufficient reproducibility of this process, a great number of samples were needed to obtain reliable results. Samples prepared for studying the dependence of strength of joints on ageing were designed to ensure maximum reproducibility of results. $\mathrm{Cu}$ plates with dimensions of $50 \mathrm{~mm} \times 8 \mathrm{~mm} \times$ $2 \mathrm{~mm}$ were first cut in the middle using a diamond saw to make a $6 \mathrm{~mm}$ deep groove of $0.5 \mathrm{~mm}$ width. These prefabricated parts were then preheated and dipped into the soldering bath. The solder filled the groove. After cooling, the bonding $\mathrm{Cu}$ segment was cut off, and a simulated solder joint with a precise gap was obtained.

\section{Results and discussion}

\subsection{The morphology of IMC layer after soldering}

In the SC alloy, the IMC layer of $\mathrm{Cu}_{6} \mathrm{Sn}_{5}$ phase formed during the first seconds after dipping the substrate into the molten solder and did not grow any further (Fig. 1a). An intensive substrate dissolution was observed. This behavior is different from what other authors commonly describe when performing experiments by reflowing a small amount of solder on the substrate [8]. They are reporting an increasing thickness of the IMC layer with time and temperature of the reaction. During the reflowing process, the small amount of solder is quickly enriched by dissolute copper from the substrate to thermodynamically equilibrium concentration (given by temperature) and after reaching this state the IMC layer starts to grow in thickness [9]. In our case, when the samples were prepared in a virtually infinite reservoir of molten solder with constant composition, the IMC layer did not grow. Rare regions of several tens of micrometers in diameter are observed where uniform layer of $\mathrm{Cu}_{3} \mathrm{Sn}$ phase was formed on the interface between substrate and $\mathrm{Cu}_{6} \mathrm{Sn}_{5}$. In places where $\mathrm{Cu}_{3} \mathrm{Sn}$ was formed, further dissolution of the substrate was prevented.
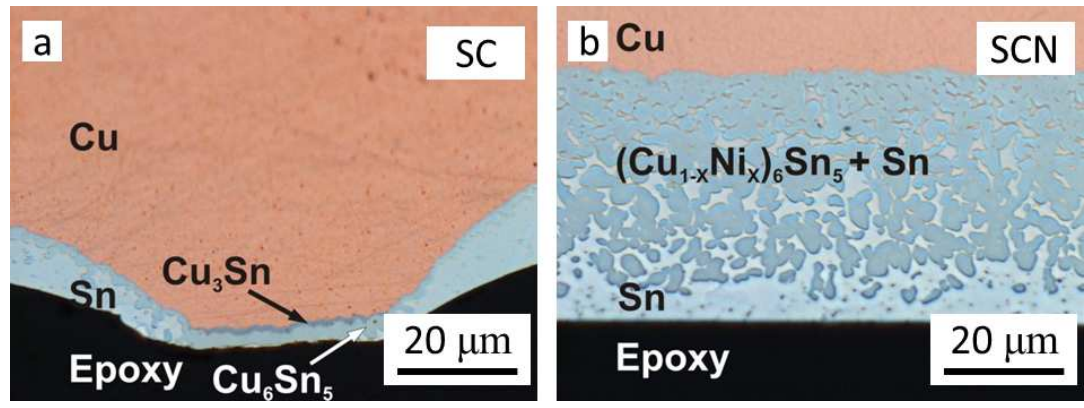

Fig. 1. Morphology of IMC layers after soldering (light microscope).

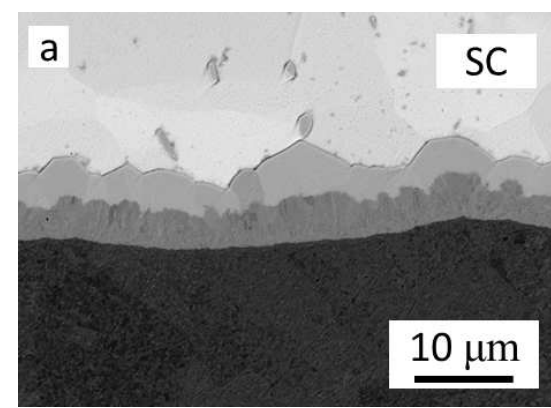

Fig. 2. Morphology of IMC layers after ageing (SEM).

In the SCN alloy which differs from SC only by addition of 0.05 wt\% of $\mathrm{Ni}$, the morphology of the IMC layer is completely different (Fig. 1b). With increasing

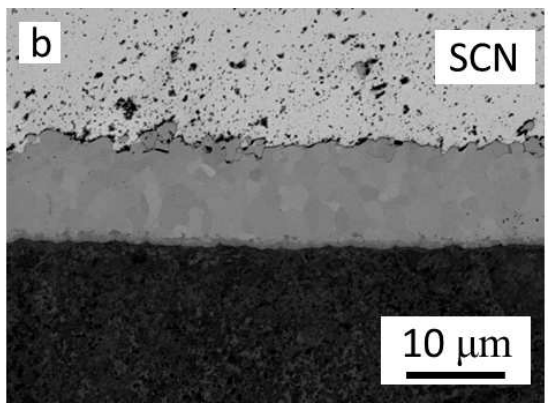

reaction time its thickness grows. Growth kinetics is even faster than in binary $\mathrm{Sn}-\mathrm{Cu}$ alloy during reflowing experiments. The morphology of the layer is not typically 
scallop-type but more uniform with entrapped solder "islands" surrounded by the $(\mathrm{CuNi})_{6} \mathrm{Sn}_{5}$ IMC phase containing $5-10$ at.\% of $\mathrm{Ni}[9]$. At any temperature and even at the longest reaction time, no layer of $\mathrm{Cu}_{3} \mathrm{Sn}$ phase was observed.

\subsection{The morphology of IMC layer after ageing}

During ageing at elevated temperature, the IMC layers further grow. In near eutectic alloy, SC scallops of $\mathrm{Cu}_{6} \mathrm{Sn}_{5}$ phase grow (Fig. 2a). Adjacent scallops coalesce, the large prevail and the smaller crystallites vanish. Even after the longest reaction time, the whole of the $\mathrm{Cu}_{6} \mathrm{Sn}_{5}$ layer consists of a single grain. The layer is not uniform but contains protrusions formed by each grain. At the interface between the substrate and $\mathrm{Cu}_{6} \mathrm{Sn}_{5}$ phase, the layer of $\mathrm{Cu}_{3} \mathrm{Sn}$ phase starts to form from the beginning of the ageing. It has a fine-grained structure and its thickness is almost the same as the thickness of the layer of the $\mathrm{Cu}_{6} \mathrm{Sn}_{5}$ phase.

During ageing of samples prepared in SCN alloy, a planar IMC layer consisting of small grains of $(\mathrm{CuNi})_{6} \mathrm{Sn}_{5}$ grows (Fig. 2b). It is compact without any solder islands, contrary to the layer after reaction with molten solder. Only a very thin layer of $\mathrm{Cu}_{3} \mathrm{Sn}$ phase was observed at the interface between the substrate and $(\mathrm{CuNi})_{6} \mathrm{Sn}_{5}$ phase. Growth kinetics of the IMC layer formed at samples prepared in SCN alloy is only slightly faster than in SC alloy.

\subsection{Strength of solder joints}

Sets of samples were prepared in solder bath at temperatures $240{ }^{\circ} \mathrm{C}$ and $270^{\circ} \mathrm{C}$. Three reaction times were selected $(5,20$, and $320 \mathrm{~s})$ in order to study the dependence of strength of the simulated solder joint on soldering conditions. Average values of the ultimate tensile strength for each set of samples are plotted in the graph of Fig. 3. The ultimate tensile strength of solder joints

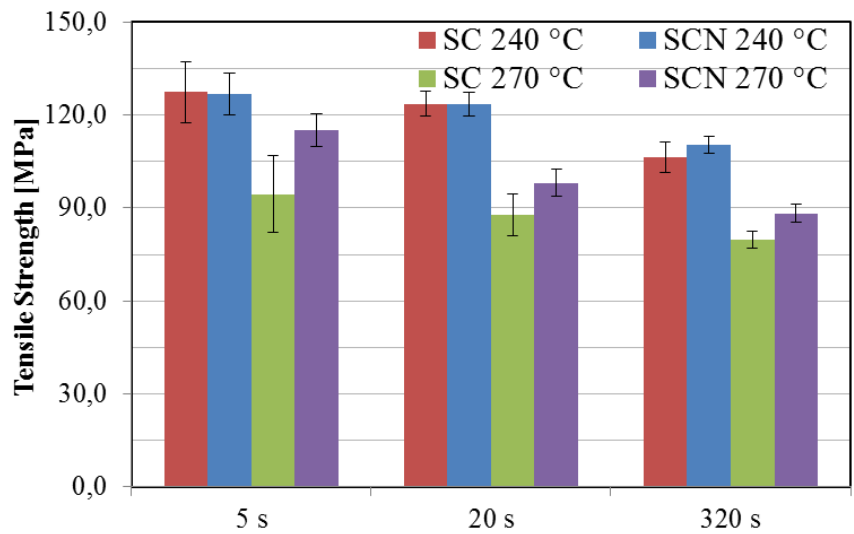

Fig. 3. UTS of solder joints after soldering.

was found to decrease both with increasing temperature of molten solder and the reaction time. The strength of solder joints prepared at $240^{\circ} \mathrm{C}$ is similar for both alloys. Samples prepared at $270^{\circ} \mathrm{C}$ in the SCN alloy exhibited significantly higher strength than samples prepared at the same temperature in the near-eutectic alloy SC. We observed a lot of defects (bubbles of evaporated flux) at the fracture surfaces of samples prepared at the shortest time. Therefore, these values have a high scatter.
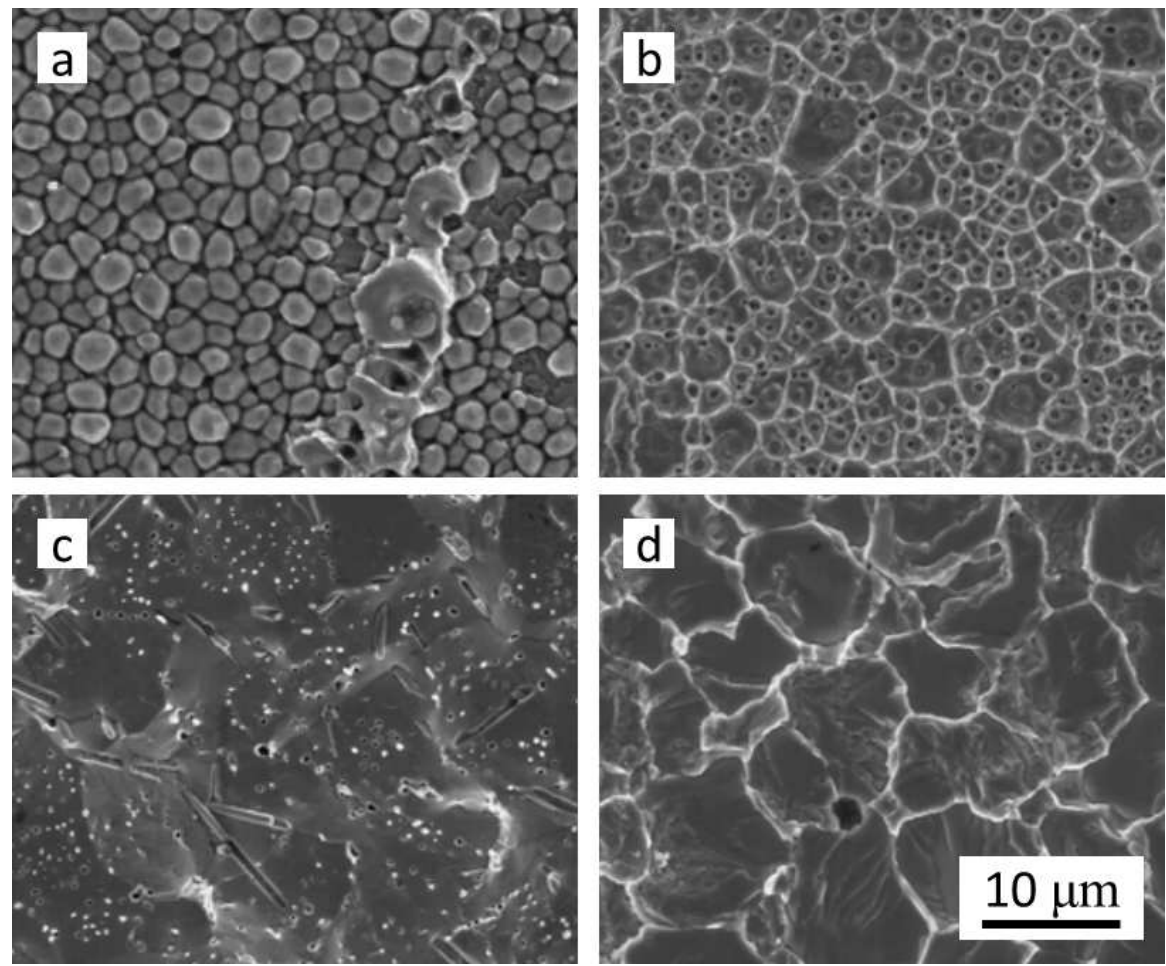

Fig. 4. Fracture surfaces: (a) brittle fracture along the IMC/solder interface, (b) ductile dimple fracture, (c) brittle intercrystalline fracture along grain boundaries of solder, (d) brittle transcrystalline fracture through IMC. 


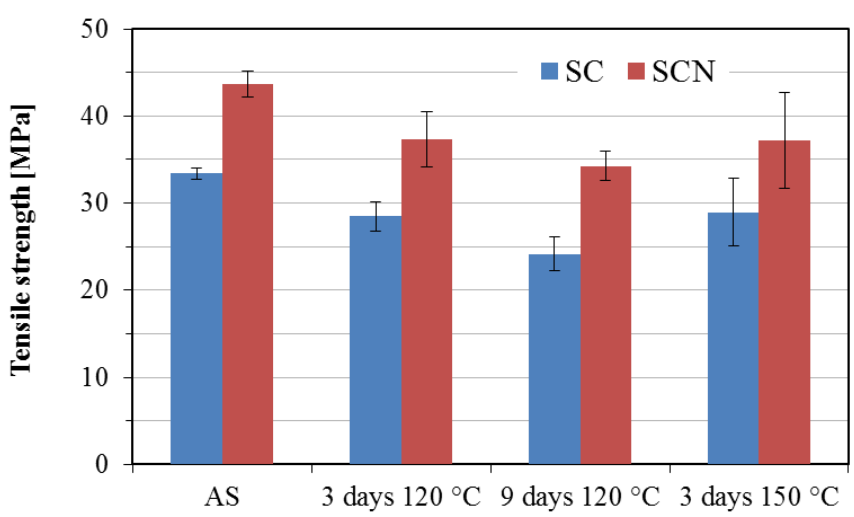

Fig. 5. UTS of solder joints after ageing.

Subsequent analysis of simulated solder joints after tensile tests revealed several different characters of fracture surfaces corresponding to different mechanisms of fracture. At shorter times (5 and $20 \mathrm{~s}$ ) we observed 3 types of fracture surfaces:

- Brittle rupture along IMC/solder interface - on one side of the fracture surface we could observe the top of the IMC layer with round crystallites of $\mathrm{Cu}_{6} \mathrm{Sn}_{5}$ and on the opposite side undeformed imprint of the IMC layer in the solder matrix (Fig. 4a).

- Ductile dimple fracture in solder bulk close to the IMC interface - initiation of fracture takes place at the interface between IMC and solder. The crack further propagates through plastically deformed bulk solder (Fig. 4b). In the center of each depression, the IMC layer is revealed.

- Brittle intercrystalline fracture along grain boundaries of solder - observed occasionally only on samples prepared in SC alloy (Fig. 4c). Samples with this type of fracture exhibit the highest ultimate tensile strength (UTS).

On samples prepared at reaction time $320 \mathrm{~s}$, we observed most often the brittle transcrystalline fracture through crystallites of IMC (Fig. 4d). Only occasionally the ductile dimple fracture was observed.

Samples for studying the effect of ageing were prepared with a larger but more precise gap between $\mathrm{Cu}$ parts which caused lower UTS but significantly increased the reproducibility of the tests. It has been shown that ageing has a similar effect on the solder joint made of both alloys. UTS decreases with increasing ageing time (Fig. 5). However, the ageing temperature has almost no effect. UTS of joints prepared in SC alloy is smaller in all conditions. Analysis of fracture surfaces most often showed ductile dimple fracture. Crack propagates along the IMC/solder interface.

\section{Conclusions}

The morphology of IMC layers and mechanical properties of simulated solder joints were investigated in samples prepared by simulated wave soldering process using the near-eutectic $\mathrm{Sn}-0.7 \mathrm{Cu}$ and $\mathrm{Ni}$ enriched $\mathrm{Sn}-0.7 \mathrm{Cu}-$ $0.05 \mathrm{Ni}$ alloys. The following conclusions can be drawn from this study:

- IMC layer in samples prepared in soldering bath with $\mathrm{Sn}-0.7 \mathrm{Cu}$ alloy does not grow with soldering time. The addition of $0.05 \mathrm{wt} \%$ of $\mathrm{Ni}$ suppresses the substrate dissolution and allows IMC layer growth.

- During ageing of samples prepared in $\mathrm{Sn}-0.7 \mathrm{Cu}$, the layer of $\mathrm{Cu}_{6} \mathrm{Sn}_{5}$ phase with single large grain across the thickness grows simultaneously with finegrained $\mathrm{Cu}_{3} \mathrm{Sn}$ phase layer of similar thickness. In case of $\mathrm{Sn}-0.7 \mathrm{Cu}-0.05 \mathrm{Ni}$ alloy, uniform IMC layer forms with a very thin $\mathrm{Cu}_{3} \mathrm{Sn}$ phase layer.

- The UTS of solder joints decreases with increasing soldering time and temperature. The fracture mechanism changes from mostly ductile to brittle. The strength of the joints also decreases with ageing time.

\section{Acknowledgments}

L. Trško acknowledges financial support by the European Regional Development Fund and Slovak State Budget under the project "Research Centre of the University of Žilina" with ITMS code 26220220183.

\section{References}

[1] F. Gao, T. Takemoto, H. Nishikawa, J. Electron. Mater. 35, 2081 (2006).

[2] F. Gao, T. Takemoto, H. Nishikawa, Mater. Sci. Eng. A 420, 39 (2006).

[3] J. Shen, M.L. Zhao, P.P. He, Y.Y. Pu, J. Alloys Comp. 574, 451 (2013).

[4] J.Y. Tsai, Y.C. Hu, C.M. Tsai, C.R. Kao, J. Electron. Mater. 32, 1203 (2003).

[5] T. Ventura, C.M. Gourlay, K. Nogita, T. Nishimura, M. Rappaz, A.K. Dahle, J. Electron. Mater. 37, 32 (2008).

[6] G.D. Li, Y.W. Shi, H. Hao, Z.D. Xia, Y.P. Lei, F. Guo, J. Alloys Comp. 491, 382 (2010).

[7] K. Nogita, C.M. Gourlay, J. Read, T. Nishimura, S. Suenaga, A.K. Dahle, Mater. Trans. 49, 443 (2008).

[8] J.F. Li, P.A. Agyakwa, C.M. Johnson, Acta Mater. 59, 1198 (2011).

[9] P. Harcuba, M. Janecek, J. Electron. Mater. 39 , $2553(2010)$ 